\title{
Life Cycle and Fecundity Analysis of Lutzomyia shannoni (Dyar) (Diptera: Psychodidae)
}

\author{
Cristina Ferro/ ${ }^{+}$, Estrella Cárdenas, Dario Corredor*, Alberto Morales, \\ Leonard E Munstermann**
}

\begin{abstract}
Instituto Nacional de Salud, Laboratorio de Entomología, Avenida Eldorado, Carrera 50, Santa Fe de Bogotá,
Colombia *Universidad Nacional de Colombia, Facultad de Agronomía, A.A. 14490, Santa Fe de Bogotá, Colombia **Departament of Epidemiology and Public Health, Yale University, School of Medicine,
\end{abstract}

60 College Street, New Haven, CT 06510, USA

The life cycle of Lutzomyia shannoni (Dyar), was described for laboratory conditions with maximum daily temperatures of $27-30^{\circ} \mathrm{C}$, minimum daily temperatures of $22-27^{\circ} \mathrm{C}$ and relative humidity between 87-99\%. Life cycle in each stage was as follows: egg 6-12 days (ave. 8.5 days); first stage larva 5-13 days (ave. 9.6 days); second stage larva 4-13 days (ave. 9.2 days ); third stage larva 5-19 days (ave. 11.8 days); fourth stage larva 7-37 days (ave. 19.9 days); pupa 7-32 days (ave. 15.2 days). The life expectancy of adults ranged from 4 to 15 days (ave. 8.6 days). The entire egg to adult period ranged from 36 to 74 days (ave. 54.6 days). On average, each female oviposited 22.7 eggs; the average egg retention per female was 24.3 eggs.

Key words: Lutzomyia shannoni - forest sand flies - life cycle - fecundity - larval description - Colombia

The sand fly Lutzomyia shannoni (Dyar) has a broad geographical distribution in Western Hemisphere from northern Argentina to southeastern United States. However, its distribution is highly disjunct within that range, depending on locally occurring environmental factors such as frequency of precipitation, temperature, physical barriers, habitat availability, and the distribution and abundance of vertebrate hosts (Young \& Arias 1992).

$L u$. shannoni was first recorded in Colombia in 1966 in tree holes at the Chigorodo location, Departament of Antioquia (Osorno et al. 1972). Since then it has been recovered from Shannon traps and resting sites on large trees from sea level up to approximately $1000 \mathrm{~m}$ (Young 1979).

In the United States of America Lu. shannoni is an important vector of vesicular stomatitis virus (VSV), a disease of cattle and sheep. Comer et al. (1991, 1994) recorded Lu. shannoni as the only sand fly present in the Ossabaw Island in Georgia

\footnotetext{
This study is part of the research project "Genetics and Biogeography of Sand Fly Disease Vectors" in collaboration with the Instituto Nacional de Salud of Colombia and Yale University, USA, and funded by a U.S. National Institutes of Health Grant (AI-34521) to LEM and the Instituto Nacional de Salud of Colombia, project No. 3100302 of the Laboratory of Entomology.

${ }^{+}$Corresponding author. Fax +57-1-222.0194

Received 18 June 1997

Accepted 11 December 1997
}

and verified that this is the insect vector of VSV there. In Panama and Colombia specimens of $L u$. shannoni have been found infected with unidentified flagelates (Johnson et al. 1963, Morales et al. 1981, Young \& Lawyer 1987, Alexander et al. 1992). Althougth $L u$. shannoni has not been associated with the transmission of severe disease in this country, it has been collected in the peridomestic environment (Pardo et al. 1996), inside houses and during human landing-biting captures (Alexander et al. 1992).

Although Lu. shannoni has been bred in the laboratory for several generations (Young et al. 1981, Endris et al. 1982) and experimentally infected with Leishmania mexicana (Lawyer et al. 1987), L. panamensis (unpublished data from the Laboratory of Entomology, Instituto Nacional de Salud) by feeding on infected hamster, and with L. chagasi (Endris et al. 1982) through membranes, very little is known about its life cycle, developmental times, mating, oviposition and larval nutrition. Although effects of colonization may strongly affect genetic constitution and behavior of a species (Munstermann 1994, Morrison et al. 1995), life table parameters for many insect species of medical importance cannot be obtained in the field.

For the past five years, the Entomology Laboratory of the Colombian INS has maintained a colony of Lu. shannoni that was initiated from specimens collected in October, 1992 in Carmen de Bolivar (Departament of Bolivar). The objective of the study is to provide baseline data concerning the life cycle and fecundity of this colony. 


\section{MATERIALS AND METHODS}

The study began at the twenty-second generation of the Lu. shannoni colony. The laboratory conditions during the study were as follows: relative humidity between 80 and $97 \%$ (ave. $88 \%$ ), maximum temperature between 27 and $30^{\circ} \mathrm{C}$ (ave. $28^{\circ} \mathrm{C}$ ), and minimum temperature between 22 and $27^{\circ} \mathrm{C}$ (ave. $25^{\circ} \mathrm{C}$ ).

The adults were kept in the same rearing chambers as used for immature forms (Fig. 1). Males and females were passed to a cloth cage only for blood feeding. The rest of the procedure was done according to Endris et al. (1982) and Modi and Tesh (1983). The females were fed on hamster blood two days after emergence. For blood feeding the females, approximately equal numbers of males and females were transferred from the rearing chamber (Fig. 1) to cloth cages $(20 \mathrm{~cm} \mathrm{x} 20$ $\mathrm{cm}$ ). Mating was observed in these cages and the rearing chambers. An anesthetized (sodium pentothal, $10 \mathrm{mg} / \mathrm{kg}$ animal weight) hamster was introduced into the cloth cages for $1 \mathrm{hr}$ to ensure adequate time for blood feeding, following the methods of Modi and Tesh (1983) for other phlebotomine species. After blood feeding, 100 females were separated into individual oviposition rearing chambers. Water and glucose $(60 \%)$ were provided in cotton swabs placed on the muslin covering of each chamber. The rearing chambers were kept in two large Styrofoam boxes with a hygrometer and maximum-minimum thermometer. The rearing chambers measured $5.5 \mathrm{~cm}$ high and $6.6 \mathrm{~cm}$ in diameter with the bottom lined with $1.5 \mathrm{~cm}$ of plaster of Paris.

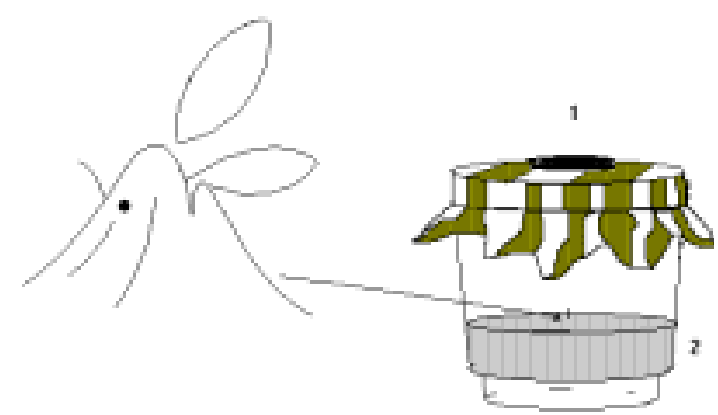

Fig. 1: scheme of the larval rearing chamber used in the study. (1) Rubber cover for the hole in the cloth through which the Lutzomyia shannoni females were introduced by aspirator. (2) Moist gypsum (plaster of Paris) layer which serves as the oviposition substrate and floor of the larva and pupa rearing chamber.

Each chamber was inspected daily with a stereomicroscope to record (a) oviposition and eggs total, (b) eggs hatch and number of larvae, (c) time of instar transition and (d) emergence times and sex of adults. Temperature and relative humidity were recorded daily. Fertility and fecundity were determined by detailed counts of eggs oviposited and those retained. Retained eggs were counted by dissection after the females died.

The larval diet for rearing was made according to Young et al. (1981) with the following changes: bovine manure and dog food instead of dry rabbit feces and Purina Rabbit Chow. It was stored for approximately three months and stirred every two weeks.

\section{RESULTS AND DISCUSSION}

\section{DESCRIPTION OF THE DEVELOPMENT INSTARS}

Egg - The eggs of the Lu. shannoni were dark brown in color with polygonal sculpturing over the chorion similar to other species of Lutzomyia (Forattini 1973, Ferro et al. 1987). The eggs were elongated oval, approximately $310 \mu \mathrm{m}$ long and $95 \mu \mathrm{m}$ wide. The females required vertebrate blood for the maturation of the follicles, and the first oviposition began between four and eight days after blood ingestion.

In the rearing chamber, a majority of the females oviposited on the humid layer of gypsum. However, some females oviposited on the glass walls of the rearing chamber; these eggs were removed to the gypsum surface with a fine brush. The average duration for the egg stage was 8.5 days with a range of 6 to 12 days (Figs 2, 3).

First instar larvae - Immediately after the first instar larvae emerged from the egg, the body color was pale cream, while the head, caudal lobule and caudal setae were light brown. The body length measured between 400 and $675 \mu \mathrm{m}$ (ave. $512 \mu \mathrm{m}$ ). The two caudal setae, just after eclosion, measures approximately twice the length of the body. Its hypognathous head was well developed and measured between 65 and $75 \mu \mathrm{m}$ wide (ave. 73 $\mu \mathrm{m}$ ) and between 35 and $50 \mu \mathrm{m}$ long (ave. 46 $\mu \mathrm{m}),(\mathrm{n}=20)$. In the middorsal cranium, the egg perforating organ extruded in the form of a sclerotized punch. The cranial exoskeleton did not show a dorsal suture. The antennal tubercle was larger than the complete antenna. The first antennal segment was long and thin; the second was almost the same size in oval form, with a hair or arista.

Feeding activity began within minutes after eclosion. The first stage larvae apparently preferred organic matter of plant origin, since they were observed devouring the small bits of grass in the manure. The first instar lasted an average of 9.6 days and a range between 5 and 13 days (Figs 2, 3).

Second instar larvae - The color was similar to that of the first instar but this instar was larger in 


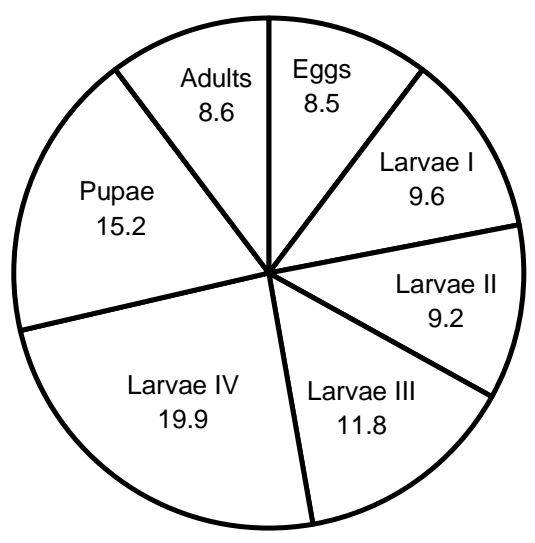

Fig. 2: life cycle of Lutzomyia shannoni obtained under laboratory conditions: average development time in days for each stage.

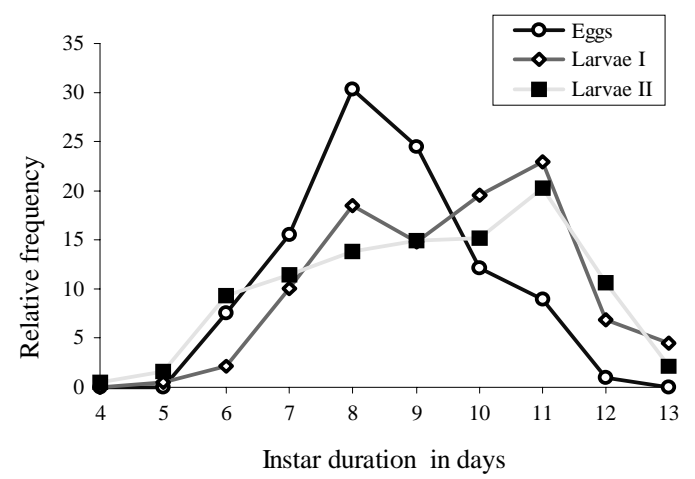

Fig. 3: comparison of laboratory colony development times (in days) in the first three instars of Lutzomyia shannoni.

size, with four caudal setae approximately twice the body length. A Y-form dorsal suture was present in the head capsule. The duration of this instar was from 4 to 13 days (ave. 9.2 days) (Figs 2, 3).

Third instar larvae - The color was similar to that of the first two instars but it was larger, and again, it had four caudal setae and a Y-form dorsal suture in the head capsule. The duration of this stage ranged from 5 to 19 days (ave. 11.8) (Figs $2,5)$.

Fourth instar larvae - The body length measured between 2200 and $2500 \mu \mathrm{m}$ (ave. 2336, $\mathrm{n}=20$ ). The caudal setae measured approximately the same as the body length. The hypognathous head (Fig. 4A) measured between 225 and $250 \mu \mathrm{m}$ wide (ave. $230 \mu \mathrm{m}$ ) and between 150 and $175 \mu \mathrm{m}$ long (ave. $172 \mu \mathrm{m})(\mathrm{n}=20)$. Four well defined stemmata and two setae with a round and prominent base were present on each side of the head and in the mandibles. They were possibly sensilla, while the head of the larvae of Lu. longipalpis was prognathous and bore two well-defined stemmata on each side. Although Hanson (1968) described the head of fourth instar $L u$. shannoni, he did not mention these photoreceptors. The tergal plaque of the eighth abdominal segment and the caudal lobule were black, similar to fourth instar larvae of other Lutzomyia. No locomotive organs protruded from the thorax, although each abdominal segment bore one central pseudopodium (Fig. 4B) per segment (except the eighth segment). Forattini (1973) also

A
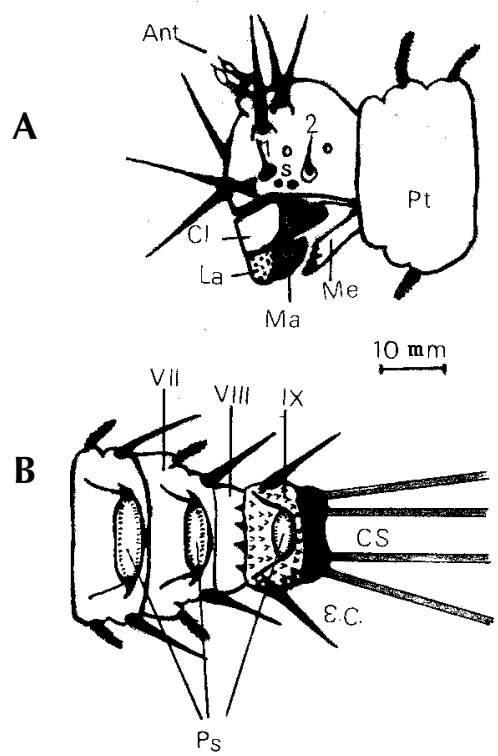

Fig. 4: scheme of the fourth instar larvae of Lutzomyia shannoni. A: hypognathous head and prothorax Pt, lateral view. Ant, antenna; 1 and 2, photorreceptor sensillum; s, stemmata; $\mathrm{Cl}$, clypeus; La, labrum; Ma, mandible; Me, mentum. B: last abdominal segments, ventral view. Ps, abdominal pseudopodia; CS, caudal setae.

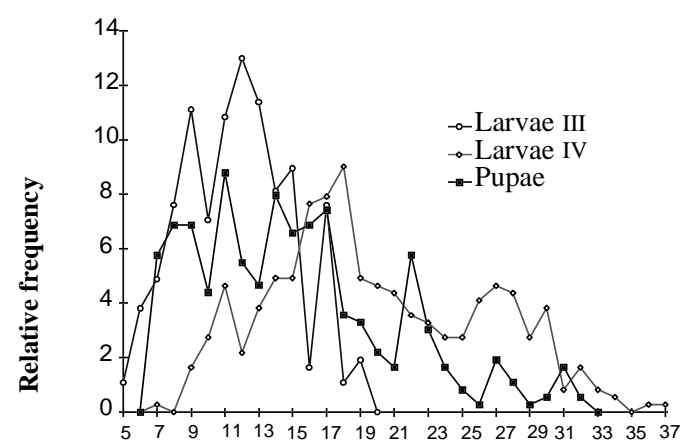

Instar duration in days

Fig. 5: comparison of third stage larvae, fourth stage larvae and pupae for number of days spent in each stage for colonized Lutzomyia shannoni. 
found no pseudopodia on the eighth abdominal segment of other sand fly larvae species. The fourth instar duration ranged from 7 to 37 days (ave. 19.9 days) (Figs 2, 5).

Pupa - Obtected, measured approximately $2600 \mu \mathrm{m}$ in length. It was glued to the substrate by the terminal abdominal segments consisting of the terminal pseudopodium of the ninth abdominal segment and the entire exuvium of the fourth instar larva. The pupal period ranged from 7 to 32 days (ave. 15.2 days) (Figs 2, 5).

Adults - The longevity was between 4 and 15 days (ave. 8.6 days) (Fig. 2). The total egg to adult period ranged from 36 to 74 days (ave. 54.6 days).

Barretto, in a 1942 publication cited by Forattini (1973), presented the life cycle of $L u$. shannoni at temperatures between 19.5 and $22.5^{\circ} \mathrm{C}$ as follows: egg stage ranging between 9 and 13 days, larva period ranging between 31 and 46 days, pupa period of 15 days and total range between 50 and 74 days. Comparing these results with the results found for $L u$. shannoni in present study, we observed little variation in the egg stage, however, in the other stages of development we observed considerable variation.

Fecundity analysis - As seen in the Table, 8\% of the females neither oviposited nor retained eggs in spite of a full blood meal. Eleven percent of the females did not oviposit but retained an average 34.4 eggs. Females survival was proportional to numbers of eggs laid and inversely proportional to eggs retained. Since more than half of the eggs were retained by the females, the laboratory conditions probably were not sufficiently favorable for oviposition.

Field-collected females of this species very rarely were found with retained eggs, and never more than one. On average, each female oviposited 22.7 eggs. The average egg retention per female was 24.3 eggs. The average total fecundity per female was of 47.0 eggs.

\section{ACKNOWLEDGEMENTS}

To Dr Gonzalo Martínez for the insect drawing (Fig. 1), and Mr Ariel Barrera for the computer adaptation of the rearing chamber illustration.

\section{REFERENCES}

Alexander JB, Ferro C, Young DG, Morales A, Tesh RB 1992. Ecology of phlebotomine sand flies (Diptera: Psychodidae) in a focus of Leishmania (Viannia) brazilienzis in Northeastern Colombia. Mem Inst Oswaldo Cruz 87: 387-395.

Comer JA, Kavanaugh DM, Stallknecht DE, Corn JL 1994. Population dynamics of Lutzomyia shannoni (Diptera: Psychodidae) in relation to the epizootiology of vesicular stomatitis virus on Ossabaw Island, Georgia. J Med Entomol 31: 850-854.

Comer JA, Stallknecht DE, Corn JL, Netles VF 1991. Lutzomyia shannoni (Diptera: Psychodidae): a biological vector of the New Jersey serotype of vesicular stomatitis virus on Ossabaw Island, Georgia. Parassitologia 33 (Suppl. 1): 151-158.

Endris RG, Perkins PV, Young DG, Johnson RN 1982. Techniques for laboratory rearing sand flies (Diptera: Psychodidae). Mosquito News 42: 400407.

Ferro C, Morales A, Cura E 1987. Morfología de los estadios inmaduros de Lutzomyia walkeri (Newstead, 1914) (Diptera: Psychodidae). Biomédica 7: 26-34.

Forattini OP 1973. Entomologia Médica, Vol. 4, Universidade de São Paulo, Brazil, 658 pp.

Hanson WJ 1968. The Immature Instars of the Subfamily Phlebotominae in Panama (Diptera: Psychodidae), $\mathrm{PhD}$ Thesis, University of Kansas, Lawrence, Kansas. USA, 104 pp.

Johnson PT, McConnell E, Hertig M 1963. Natural and experimental infections of Leptomonad flagellates in Panama Phlebotomus sandflies. Exp Parasitol 14: 107-122.

Lawyer PG, Young DG, Butler JF, Akin DE 1987. Development of Leishmania mexicana in Lutzomyia diabolica and Lutzomyia shannoni (Diptera: Psychodidae). J Med Entomol 24: 347-355.

Modi GB, Tesh RB 1983. A simple technique for mass rearing Lutzomyia longipalpis and Phlebotomus papatasi (Diptera: Psychodidae) in the laboratory. $J$

TABLE

Fecundity and survival of Lutzomyia shannoni females

\begin{tabular}{lcrrr}
\hline & \multicolumn{4}{c}{ Average } \\
\cline { 2 - 5 } Characteristics of the females & $\begin{array}{c}\text { Observed } \\
\text { females }\end{array}$ & $\begin{array}{c}\text { Oviposited } \\
\text { eggs }\end{array}$ & $\begin{array}{c}\text { Retained } \\
\text { eggs }\end{array}$ & $\begin{array}{r}\text { Total } \\
\text { eggs }\end{array}$ \\
\hline Death, no oviposition, no retained eggs & 8 & 0 & 0 & 0 \\
Death, no oviposition, with retained eggs & 11 & 0 & 34.4 & 34.4 \\
Oviposition and death & 42 & 16 & 35.6 & 51.7 \\
Oviposition and one-day survival & 23 & 38.5 & 15.3 & 53.8 \\
Oviposition and two-days survival & 13 & 40.2 & 13.7 & 53.9 \\
Oviposition and three-days survival & 2 & 69 & 7.5 & 76.5 \\
Oviposition and four or more days survival & 1 & 51 & 11 & 62 \\
\hline Total & 100 & 2274 & 2429 & 4703 \\
\hline
\end{tabular}


Med Entomol 20: 568-569.

Morales A, Corredor A, Cáceres E, Ibagos AL, Rodríguez C 1981. Aislamiento de tres cepas de Leishmania a partir de Lutzomyia trapidoi en Colombia. Biomédica 1: 198-207.

Morrison AC, Munstermann LE, Ferro C, Pardo R, Torres M 1995. Ecological and genetic studies of Lutzomyia longipalpis in a central Colombia focus of visceral leishmaniasis. Bol Malariol Saneamiento Ambiental 35 (suppl. 1): 235-248.

Munstermann LE 1994. Unexpected genetic consequences of colonization and inbreeding: allozyme tracking in Culicidae. Ann Entomol Soc Am 87: 157164.

Osorno E, Morales A, Osorno F de, Ferro C 1972. Phlebotominae de Colombia (Diptera: Psychodidae) IX. Distribución geográfica de especies de Brumptomyia Franca y Parrot, 1921 y Lutzomyia Franca, 1924 encontradas en Colombia. Rev Acad
Colomb Cienc Exactas Fis Nat 14: 45-68.

Pardo RH, Farietta S, Munstermann LE, Ferro C. 1996 Estudio preliminar de los flebótomos de Villeta y Quebradanegra (Cundinamarca), implicaciones en salud pública. Biomedica 16: 293-302

Young DG 1979. A Review of the Bloodsucking Psychodid Flies of Colombia (Diptera: Phlebotominae and Sycoracinae), Tech Bull 806, Agric Exp Station, IFAS, Univ. Florida, Gainesville, 226 $\mathrm{pp}$.

Young DG, Arias JA 1992. Flebótomos: vectores de leishmaniasis en las Américas, Org. Pan-Amer, Salud, Tecnical Report No. 33.

Young DG, Lawyer PG 1987. New World vectors of the leishmaniases. Current Topics in Vector Research 4: 29-71.

Young DG, Perkins PV, Endris RG 1981. A larval diet for rearing phlebotomine sand flies (Diptera: Psychodidae). J Med Entomol 18: 446. 
